\title{
Systems Theory and Thinking as a Foundational Theory in Human Resource Development-A Myth or Reality?
}

\section{Robert M.Yawson'}

\begin{abstract}
This study reviews systems theory and thinking (ST\&T) as a foundational discipline or theory in human resource development (HRD) research and practice. Using systematic evidence review (SER) of the literature and mapping analysis of HRD curricula across some leading U.S. universities, disconnect between theory and practice of ST\&T is discussed. The use of SER of the literature in HRD research is an important aspect of this study. The study recommended the incorporation of more ST\&T courses into the HRD undergraduate and graduate curricula. Recommendations of how systems thinking can become more relevant to HRD research and practice are offered.
\end{abstract}

\section{Keywords}

curricula, systems dynamics, complexity theory, systems thinking, learning, epistemology

\section{The Importance of Systems Theory in Practice}

There seems to be a broad agreement in the field of human resource development (HRD) that systems theory and thinking (ST\&T) is a crucial component of the research and practice in HRD (e.g., Ardichvili, 2008; Hartshorn, 1989; Iles \& Yolles, 2003; Lee, 2003; McLagan, 1989; Swanson, 2001; Swanson \& Holton III, 2008). Practice as used in this study encompasses scholarly practice (research and teaching)

'University of Minnesota, Minneapolis, MN, USA

\section{Corresponding Author:}

Robert M. Yawson, Department of Organizational Leadership, Policy, and Development, College of Education and Human Development, University of Minnesota, 330 Wulling Hall, 86 Pleasant Street SE, Minneapolis, MN 55455, USA

Email:yawso003@umn.edu 
and practice in terms of working with organizations. However, the apparent lack of applications of systems thinking by HRD practitioners, professionals, researchers, and students raises the question why a theory generally accepted as a foundational theory is not seen in practice and in learning as it should.

Iles and Yolles (2003) have attributed the apparent lack of applications of ST\&T in HRD practice and research to the several limitations of current HRD as a field of study due to its over reliance on simple systems model of input-output transformation. Jayanti (2011) has also contended that "linear epistemology is the dominant epistemology in the field of HRD and as such undergirds a majority of HRD models" (p. 101) and argues further that these models have served HRD well but can no longer be the dominant epistemology.

In an editorial in Human Resource Development Review, Yorks and Nicolaides (2006) made an important observation that much HRD theory and research treat organizational systems as complicated linear systems instead of nonlinear dynamic, interdependent systems. If ST\&T is generally acknowledged as a foundational discipline or theory in HRD then it is quite paradoxical to have linear epistemology as the dominant epistemology. This paradox may be due to how HRD professionals view ST\&T. Gene L. Roth as president of the Academy of Human Resource Development (AHRD) acknowledged that systems theory has been proposed as a logical starting point for examining HRD (Roth, 2004). Roth (2004), however, contended that like the field of HRD, lack of consensus regarding the boundaries of ST\&T might also influence how HRD professionals may use ST\&T in research and practice based on the competing contentions that reside in the literature on the parameters of ST\&T. For example, HRD has several formulas such as analysis, diagnosis, intervention development, implementation, and evaluation (ADDIE); learning models; action research; planned change; field theory; performance improvement; and learning organization models, for addressing individual and organization change, but has little to show on how the discipline addresses the intricacies of power, politics, and culture in organizations (Bierema \& Eraut, 2004).

Vakili, Izadi, and Moteabbed (2007), in discussing the understanding of barriers to ST\&T, indicated that researchers and professionals who articulate the concept do not seem to apply it in practice and decision-making. In any field of practice, "formal theoretical explorations are much more likely to be attended to if their relevance to, and implications for, practice are clearly established" (Brookfield, 1992, p. 85). A persuasive argument can thus be made that for ST\&T to be accepted as a foundational theory in HRD, its relevance and application in HRD practice must be unambiguous. As Brookfield (1992) clearly articulated:

In a field of practice formal theoretical elaborations gain credibility (or come to be seen as irrelevant) through a process by which practitioners judge the accuracy and validity of these elaborations in a range of practical contexts. To propose formal theoretical insights without exploring their connections to practice 
effectively renders them closed to the majority ... working across the varied contexts in the field (p. 86)

The issue of relevance in practice of ST\&T as a foundational theory in HRD is therefore critically important. Raelin (2007) stated that "we may not realize that one of theory's main purposes is to inform practice, nor may we be aware that theory loses much of its vitality if uninformed by reflection on practice" (p. 495), what Raelin (2007) referred to as epistemology of practice.

The questions arising are: Has ST\&T had an impact on how HRD is studied and practiced? Have the contributions to scholarly research in ST\&T in HRD any way shaped the way HRD has evolved and continues to evolve as discipline, in both research and practice? Why the disconnect between theory and practice of ST\&T in HRD if it is seen as one of the foundational theories or disciplines? Are future HRD professionals being adequately trained to understand the importance and role of ST\&T in the research and practice of HRD? Finally, is ST\&T as a foundational theory in HRD a myth or reality? This article attempts to answer these questions and also set the tone for future research.

The purpose of this study is therefore to analyze the disconnect between the theory and practice of ST\&T in HRD. An attempt is also made to understand whether ST\&T as a foundational discipline or theory in HRD is a myth or reality? Recommendations of how systems thinking can become more relevant to HRD research and practice are offered.

The study follows a logical expository approach including the following:

- A narrative review of the literature on ST\&T to place it in the realm as a discipline of study on its own (Sterman, 2000).

- Systematic evidence review (SER) of "ST\&T in HRD" literature is conducted to understand the epistemology of ST\&T in HRD to ascertain why it is generally accepted as a foundational theory.

- The study then identifies and offers explanations of the reasons for disconnect between theory and practice.

- The study maps and analyzes courses offered in several of the leading HRD departments in U.S. universities to critique whether the course offerings are the true reflections of how researchers and professionals articulate the concept; and also to answer the question as to whether future HRD professionals are being adequately trained to understand the importance and role of ST\&T in the research and practice of HRD.

In a way this study is also motivated by Kuchinke's (2007) admonition that "HRD should be encouraged to become increasingly self-critical by investigating and discussing to a greater extent the aims and means, explicit and implicit, of the curriculum" (p. 123) and this study attempts to do just that. 


\section{Systems, Systems Theory, and Systems Thinking}

Systems theory has been variously defined in the literature. It is however, important that before systems theory is discussed the word "systems" is defined. It is one of the most loosely used words both in everyday discourse and in academic literatures. It is defined as "a group of interacting components that conserves some identifiable set of relations with the sum of their components plus their relationships (i.e., the system itself), conserving some identifiable set of relationships to other entities (including other systems)" (Straussfogel \& Schilling, 2009, p. 151). All occurrences are interconnections of relationships among component parts of a system.

\section{Systems Theory}

Systems theory, also referred to as general systems theory or systemics, is the theory underlying the study of systems. Systems theory has a very long history, but as the core theory underlying an academic discipline, its foundation is generally accredited to Karl Ludwig von Bertalanffy, an Austrian-born biologist with his development of General Systems Theory (GST). It is important to note that systems theory does not represent just a single theory, but a set of constructs that coevolved with a set of related intellectual streams concerned with the nature and characteristics of systems (Straussfogel \& Schilling, 2009). These include information and game theory, cybernetics and chaos theory, theory of autopoiesis, complexity theory, and dynamic systems theory (Straussfogel \& Schilling, 2009). It is a trans- and interdisciplinary theory that underlies studies of complex systems in nature, society, organizations, and science. Systems theory is therefore a theoretical framework by which elements that act in concert to produce some result are studied. Principia Cibernetica Web defines systems theory as the "transdisciplinary study of the abstract organization of phenomena, independent of their substance, type, or spatial or temporal scale of existence. It investigates both the principles common to all complex entities, and the (usually mathematical) models which can be used to describe them" (Heylighen, 2000, webpage). Systems theory can be classified into three broad categories.

Hard systems: This is the category of systems theory that uses simulations, and takes a narrow view at the conversion of inputs into outputs for attainment of particular goals and objectives (Engel, 1997) based on the use of computers and the techniques of operation research. A typical example that is still used currently by most international development agencies is that of the logical framework analysis approach, which was popularized in the 1970s (Morgan, 2005). It is also the predominant systems approach in HRD scholarship (Iles \& Yolles, 2003). Hard systems are valuable for problems that can reasonably be quantified. The most important drawback of its use is that it is not applicable to important concepts such as culture, politics, and opinions that cannot be easily quantified.

Soft systems: In contrast to hard systems, soft systems approach is used for systems that cannot easily be quantified (Checkland \& Scholes, 1990). It has found very useful 
applications in cases involving people with various and conflicting frames of reference. It is used for understanding motivations, opinions, and interactions, and takes account of both qualitative and quantitative dimensions of problem situations (Checkland \& Scholes, 1990).

Dynamic systems: It is the systems approach for understanding the design of complex social systems. Dynamic systems incorporate critical systems inquiry with soft system methodologies (Bánáthy, 1996). Dynamic systems as evolutionary systems are open and complex systems, with inherent nature of changing or evolving with time (Bánáthy, 2000). Dynamic systems include chaos, complexity, and cybernetics.

\section{Systems Thinking}

Systems thinking is predicated on the principles of systems theory in that the constituent parts of a system will exhibit different behavior and properties when it is viewed in isolation from the whole. To understand a system, is therefore to study the systems relationships that exist between the various parts that work in concert to determine the behavior of the system. The primary concern of systems thinking is, therefore, how the "whole" is seen and its fit and relationship to its environment. A secondary emphasis is placed on the component parts of the system.

Dimensions of systems thinking: Four dimensions of systems thinking have been described (Ossimitz, 2000; Raymond, 2003; Sterman, 2000):

- Thinking in models and interrelated structures using Causal Loop Diagrams to transfer the gained knowledge to real situations.

- Dynamic thinking that mostly uses behavior over time graphs to anticipate future behavior of systems with delays, oscillations, and feedback loops.

- Integrated thinking using stock and flows to consider complex linkages as opposed to linear thinking, where one cause is thought to have only one effect.

- Systems action-successful acting in complex situations by finding right leverage points for action, using systems archetypes.

Features of systems thinking: The characteristics, features, and properties of any system emanate from the multitude of interrelationships that exist between the component parts. Little about the whole system can be inferred from studying the workings of individual elements. The focus is on the behavior of the inseparable whole.

\section{Complex Systems}

One important aspect of a systems research is the complexity of systems. A complex system is defined as a system which is made up of interconnected parts that exhibit concerted properties as a whole which are different from the properties exhibited by the individual constituent parts when acting alone. A complex system is either a disorganized or organized complexity. 
Yorks and Nicolaides (2006) in discussing the notion of centrality of ST\&T to HRD theory, made a clear distinction between systems that are complicated and those that are complex. "Complicated systems may appear complex but can be deconstructed and usually function in a linear way; complex systems may seem simple but are dynamic, ever interacting as they evolve in a nonlinear way" (Yorks \& Nicolaides, 2006 , p. 145). Systems with huge number of parts are mostly disorganized whereas organized complexity normally has limited components and a subject system that exhibit emergent properties.

There are different types of complex systems: chaos theory and its offshoots complexity theory and complex adaptive systems (CAS) are underlined by the features of systems theory, although they may represent a new and distinct generation of thought. These theories maintain that "relationships in complex systems, like organizations, are non-linear, made up of interconnections and branching choices that produce unintended consequences and render the universe unpredictable" (Tetenbaum, 1998, p. 21). Complexity theory posits "that some events, given our knowledge and technology, are unknowable until they occur, and may indeed be unknowable in advance" (Schneider \& Somers, 2006, p. 354). Complexity theory includes three interrelated elements that are not accounted for in GST. These are nonlinear dynamics, in which structures are characterized by high states of energy exchange with the environment and extreme instability (Hickman, 2010); chaos theory which is nonlinear, deterministic (rather than probabilistic), sensitive to initial conditions, and continuous irregularity in the behavior of the system (Taleb, 2007); and adaptation and evolution, in which an ability to modify or change is evidenced through a process of interdependent self-organization among individuals or subsystems (Schneider \& Somers, 2006).

Chaotic systems (random behavior): Chaos theory is one of the most misconstrued areas in systems theory. This may probably be that the word "chaos" is a misnomer since it connotes disorder. Chaos systems theory is the theory underlying understanding the behavior of systems that exist between rigid regularity and randomness based on pure chance (Ditto \& Munakata, 1995; Levy, 1994). For any systems to be described as a chaotic system, it must be nonlinear, deterministic (rather than probabilistic), sensitive to initial conditions, and continuous irregularity in the behavior of the system (Ditto \& Munakata, 1995; Levy, 1994; Taleb, 2007; Williams, 1997).

Complex adaptive systems (CAS): CAS are special cases of complex systems. The diverse and multiple interconnected elements confer the complexity. The ability to evolve, transform, and learn from experience confers the adaptive nature in such systems. There are several examples that can be listed for CAS, including the stock market, manufacturing businesses, and any human social group or group-based endeavor in a cultural and social system, among several others including biological systems. There are several tools to study complex systems and these "tools for learning about complexity must also facilitate the process of systems thinking and policy design" (Sterman, 2001, p. 22).

Cybernetics: Like the broader systems theory itself, cybernetics has various definitions. Converging the various definitions, it can be described as the study of how 
information, communication, feedback, and control specifically functions within and outside a system (Heylighen, Joslyn, \& Turchin, 2000). Major emphasis of the field of cybernetics has focused on describing the heterogeneity of interacting parts of a system such as complexity, mutuality, complementarity, evolvability, constructivity, and reflexivity (Heylighen et al., 2000; Ruona, 2008).

The foregoing illuminates the broadness of ST\&T and its emerging branches of study. This offers the opportunity for HRD scholars and practitioners to create "the theoretical discourse that provides guidance for thoughtful practice . . . in the service of enriching the connection between theory and practice" (Yorks \& Nicolaides, 2006, p. 147).

\section{SER of ST\&T in HRD Literature}

The purpose of this SER is to address the question whether ST\&T is a foundational theory or discipline in HRD. Since this is the first time SER is being specifically used in any of the mainstream HRD publications, a detailed review of its use is given.

There is a wide array of approaches to literature review and research synthesis. Research synthesis is an umbrella term for the collection of approaches for summarizing, integrating and, in some cases, cumulating the findings of different studies on a particular topic or a specific research question (Davies, 2000). This broad range includes narrative reviews, integrative reviews, realist synthesis, vote-counting reviews, meta-analyses, best evidence synthesis, meta-ethnography and SER (Davies, 2000; Davies, 2003; Gasteen, 2010; Petticrew, 2001). The simplest form of research synthesis is the traditional qualitative literature review, often referred to as the narrative review (Davies, 2003).

Traditional reviews offer a summary of a number of different studies and sometimes draw conclusions about a particular intervention or policy (Boaz, Ashby, \& Young, 2002). Narrative reviews are almost always selective, if not arbitrary, in that they do not involve a systematic, rigorous, and exhaustive search of all the relevant literature (Davies, 2000). In most instances, traditional/narrative reviews are opportunistic since they review only the literature that is readily available to the reviewer (Davies, 2000). Most narrative literature reviews deal with a broad range of issues related to a given topic rather than addressing a particular issue and usually examine the results of only a small part of the research evidence, and take the claims of authors at face value (Cook, Mulrow, \& Haynes, 1997; EPPI, 2010). "Narrative reviews, primarily based on the experience and subjective judgment of the author(s) — often expert in the area - are the traditional approach to reviews of any body of knowledge" (Goodwin \& Geddes, 2004, p. 249).

Another major limitation of narrative reviews is that "they are almost always selective in that they do not involve a systematic, rigorous and exhaustive search of all the relevant literature using electronic and print media as well as hand-searching and ways of identifying the 'grey' literature" (Davies, 2003). Narrative reviews seldom give full details of the processes and mechanics by which the reviewed literature has been identified and synthesized (Davies, 2003). It is also often not easy to determine how the 
conclusions were derived from the review (Davies, 2003; Tranfield, Denyer, \& Smart, 2003). This lack of transparency makes it difficult to determine the selection bias and publication bias of narrative reviews (Davies, 2003; Thomas \& Harden, 2003; Wright, Brand, Dunn, \& Spindler, 2007).

SERs are different from narrative reviews in that they attempt to deal with all of the limitations of narrative reviews (Cook et al., 1997; Thomas \& Harden, 2003). SERs have developed in response to an increasing need for policymakers, researchers, and education practitioners to have access to the latest research evidence when making decisions (Harden \& Thomas, 2005). SERs are a rigorous and transparent form of literature review (ODI, 2012) and they incorporate the strengths of integrative reviews, vote-counting reviews, meta-analyses, best evidence synthesis, and meta-ethnography. It has been described as "the most reliable and comprehensive statement about what works if it is done well and with full integrity" (van der Knaap, Leeuw, Bogaerts, \& Nijssen, 2008, p. 49). SERs include identifying, gathering, synthesizing, and assessing all available evidence, quantitative, and/or qualitative, in order to generate a robust, empirically derived answer to a specific research question (ODI, 2012).

Key features of an SER or a systematic research synthesis are as follows (DixonWoods, 2006; EPPI, 2010; Hemingway \& Brereton, 2009):

- Explicit and transparent methods/protocol are used

- It follows a standard set of stages

- It is accountable, replicable and updateable

- Prespecified, highly focused question

- Explicit methods for searching

- Explicit methods for appraisal

- Explicit methods for synthesis of studies

The purpose of conducting systematic reviews is to use precise process to find as much as possible of the research relevant to the particular research questions, and be able to reliably collect every relevant information that exist on the subject of study (EPPI, 2010). SER as an approach incorporates integrated literature reviews as have been described by Callahan (2010) and Torraco (2005). SER, which has primarily been used in medical intervention research, follows standard stages as mentioned earlier, and can be replicated to obtain the same results. To the best of my knowledge this is the first attempt at its use in any HRD research, although it has been used in some qualitative studies in other social science research (Petticrew \& Roberts, 2006). It must, however, be noted here that the full complement of SER as used in medical intervention research (e.g., CRD 2009; Dixon-Woods, Agarwal, Jones, Young, \& Sutton, 2005; Pope, Mays, \& Popay, 2007; Thomas \& Harden, 2008) may not all be applicable to HRD research but can be adapted to suit the needs of HRD and may also serve as alternative literature review and synthesis framework that can be used in HRD research depending on the objectives of the particular study. This article attempts to adapt the medical guidelines to the needs of HRD researchers. There are a number of issues where HRD research 
differs from medical research. In particular, HRD research has relatively little empirical research compared with the large quantities of research available on medical issues, and research methods used by HRD are mostly different from those used by medical researchers. Important steps in SER such as the peer review of the research protocol before the start of the study itself was not followed.

The overall approach to the SER for this study is adapted from the guidelines in the Cochrane Handbook for Systematic Reviews (Higgins \& Green, 2009); and guidelines for systematic reviews in the social sciences (Petticrew \& Roberts, 2006). Answering the main research question involved synthesizing quantitative and qualitative evidence. The following steps were followed: search for materials, screen studies, extract data, summarize data, perform analyses, and write up results.

\section{Search for Materials}

For the initial search for materials, literature synthesis was done using text mining (process of analyzing text to extract information that is useful for particular purposes; Witten, 2004, p. 137) to extract technical intelligence (the ability to act on technical information flexibly to understand means - end relations and specific subject affordances, pertinent to the study of interest, and complemented by suitable tacit knowledge of the researcher; Porter, Schoeneck, Frey, Hicks, \& Libaers, 2007) from ST\&T in HRD research literature. An extensive ST\&T in HRD query was applied to the Social Science Citation Index/Arts \& Humanities Citation Index (SSCI/A\&HCI) databases. A variety of terms and phrases were used in the search for materials including systems thinking/systems theory/systems foundations/chaos theory/complex systems/ social systems theory. Each of these keywords and phrases was searched in combination with the search item "human resource."

Cross-referencing and searching of the references of some key articles also occurred to obtain lists for other related studies. In addition to the citation indexes, an expansive search covering several disparate electronic databases, including, Business Source Premier, EconLit, Academic Search Premier, Google scholar, Education Full Text, and ERIC (Access via CSA), were also queried. "Handsearching" of four of the key journals in the field of HRD was done. The journals are Advances in Human Resource Development, Human Resource Development Review, Human Resource Development International, and Human Resource Development Quarterly. Handsearching involves scanning the content of journals, using the journal's own search tool. In 2007, the AHRD theory committee compiled a Theory Development in Human Resource Development Bibliography, which listed 332 articles (AHRD, 2007); and this bibliography was also included in the initial search. This expansive search resulted in 1,535 articles.

\section{Prioritization and Selection of Literature (Screen Studies)}

For the prioritization of materials, the initial searches of all materials were uploaded into Mendeley Citation Software and screened in terms of their relevance to HRD 
using abstract reviews and then the 453 most pertinent articles were identified. In order to simplify the evidence collection process, each identified source was evaluated using explicit criteria, to include and exclude studies. These criteria were adapted from Yawson and Kuzma (2010), Pope et al. (2007), and CRD's guidance for undertaking reviews, and included: the quality of the source- peer review journal publication, edited conference proceedings, report from recognized research centers and universities; the approach to the primary research and the methodology used; study specificity of how the study is situated within HRD - ST\&T studies that are not related to research and practice of HRD are excluded; the level to which the source discussed the broader research question on why ST\&T is generally accepted as a foundational theory in HRD. This resulted in a total of 163 articles.

\section{Extraction, Summarization, and Analyses of Data}

The 163 selected articles were exported to an EPPI-Reviewer 4.0: software for research synthesis (Thomas, Brunton, \& Graziosi, 2010). The articles were either imported directly from the search engine or first saved in Refworks/Zotero before exporting to EPPI-Reviewer that was used to help import data on articles and other publications into a database for easy access and manipulation. Using the following key phrases: theory building, underlying theory, foundational theory, career development, organizational development, training and development, performance improvement, and HRD, 38 articles were selected for the evidence review. Out of these 38 articles, 34 are purely theoretical/conceptual, three of the articles are studies reporting ST\&T practice, and only one (McGuire \& Cseh, 2006) of the articles is actually based on empirical research to contend that ST\&T is a foundational theory of HRD. Table 1 is the result of SER and a separate list of references has been provided for SER.

There were however, several articles in allied fields such as organizational and behavioral studies with empirical research in ST\&T which were excluded, for example Houchin and MacLean (2005) and McKelvey (1999). Other data including the most cited papers, authors with most papers, location of authors, etc. were provided by the software but are of no relevance to the objectives of this article and are therefore not discussed.

\section{Evidence Review}

From the review it is clear that ST\&T is seen as crucial component of epistemology of practice and research in the field of HRD. The major disagreement is about which disciplines constitute the foundational disciplines of HRD. Kuchinke (2001) argues that HRD is derived from five disciplines in the physical and social sciences (namely economics, psychology, sociology, anthropology, and political science). The main proponents of systems theory as the foundational theory also agree that there are other disciplines that are important to the research and practice of HRD (Holton, 1999; Iles \& Yolles, 2003; Passmore, 1997; Swanson, 1999a; Swanson \& Holton, 2001; Torraco, 


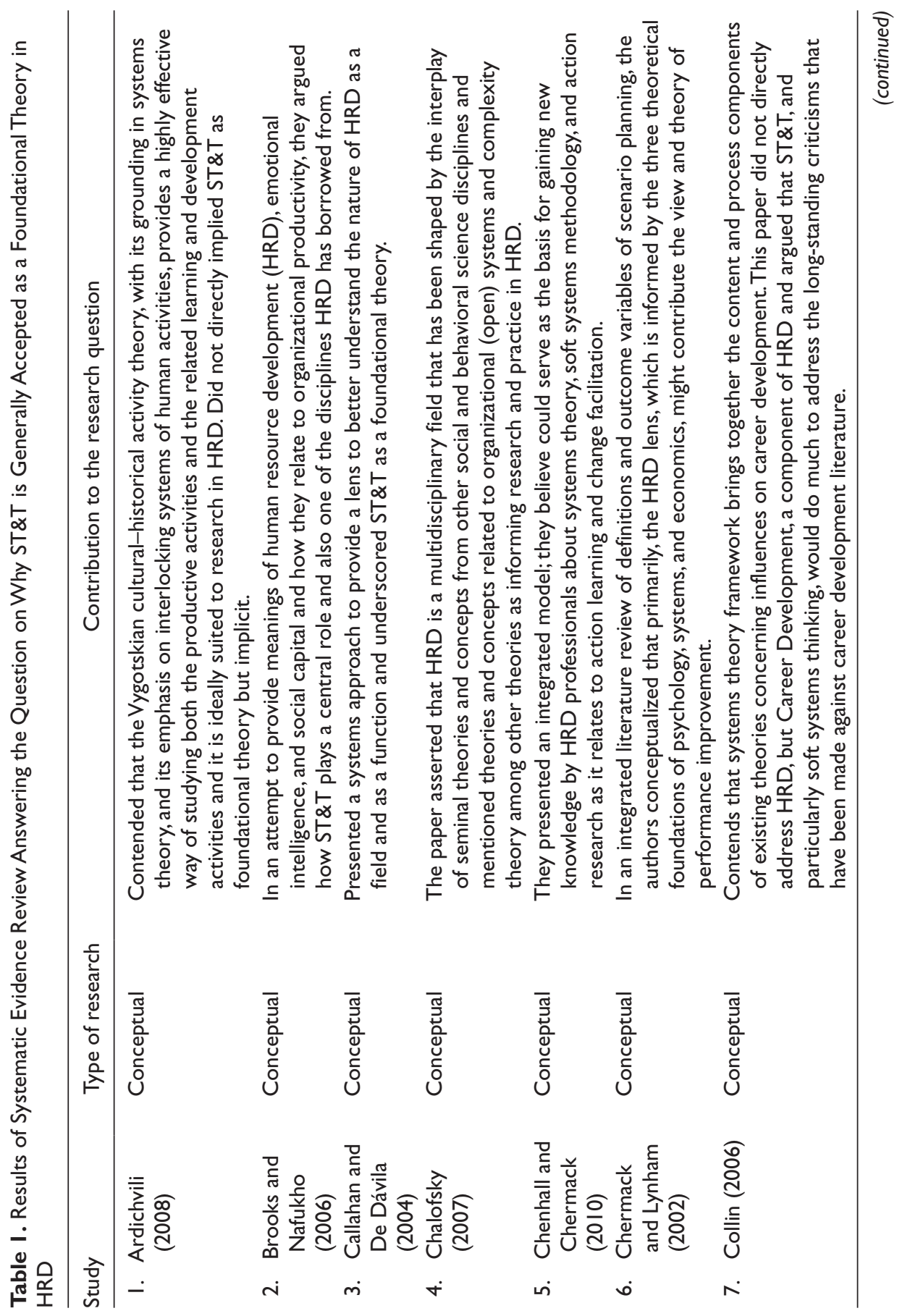









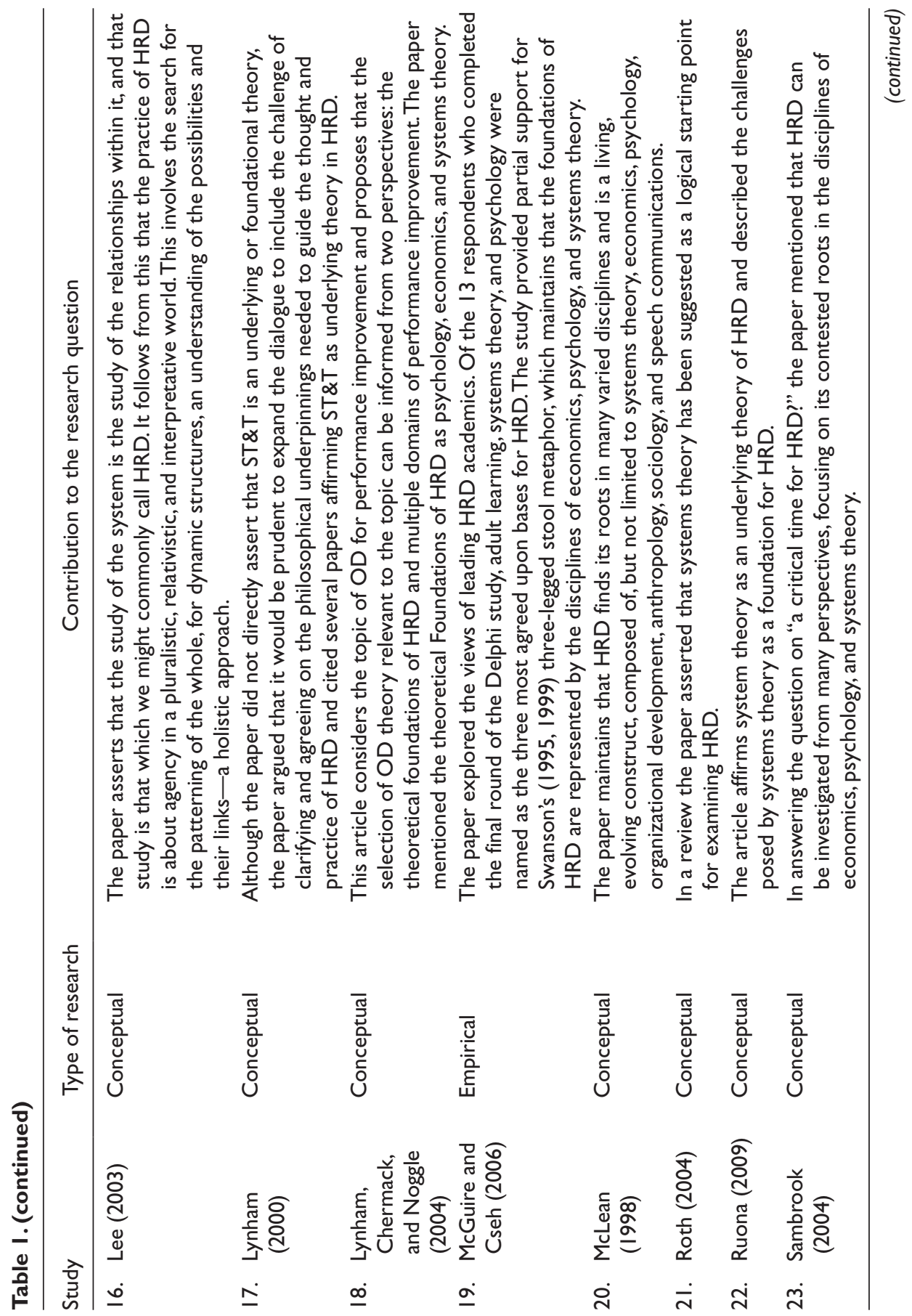




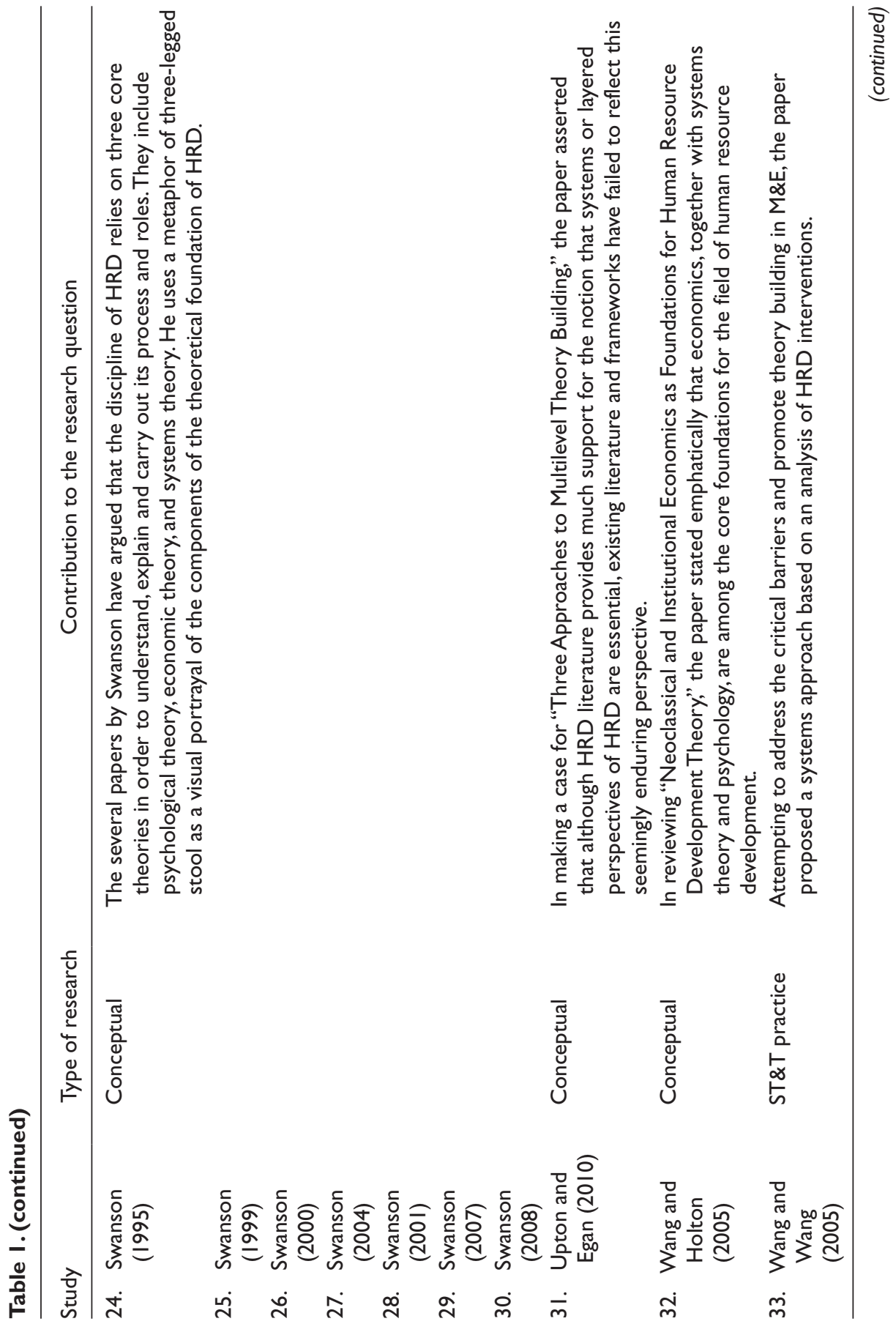




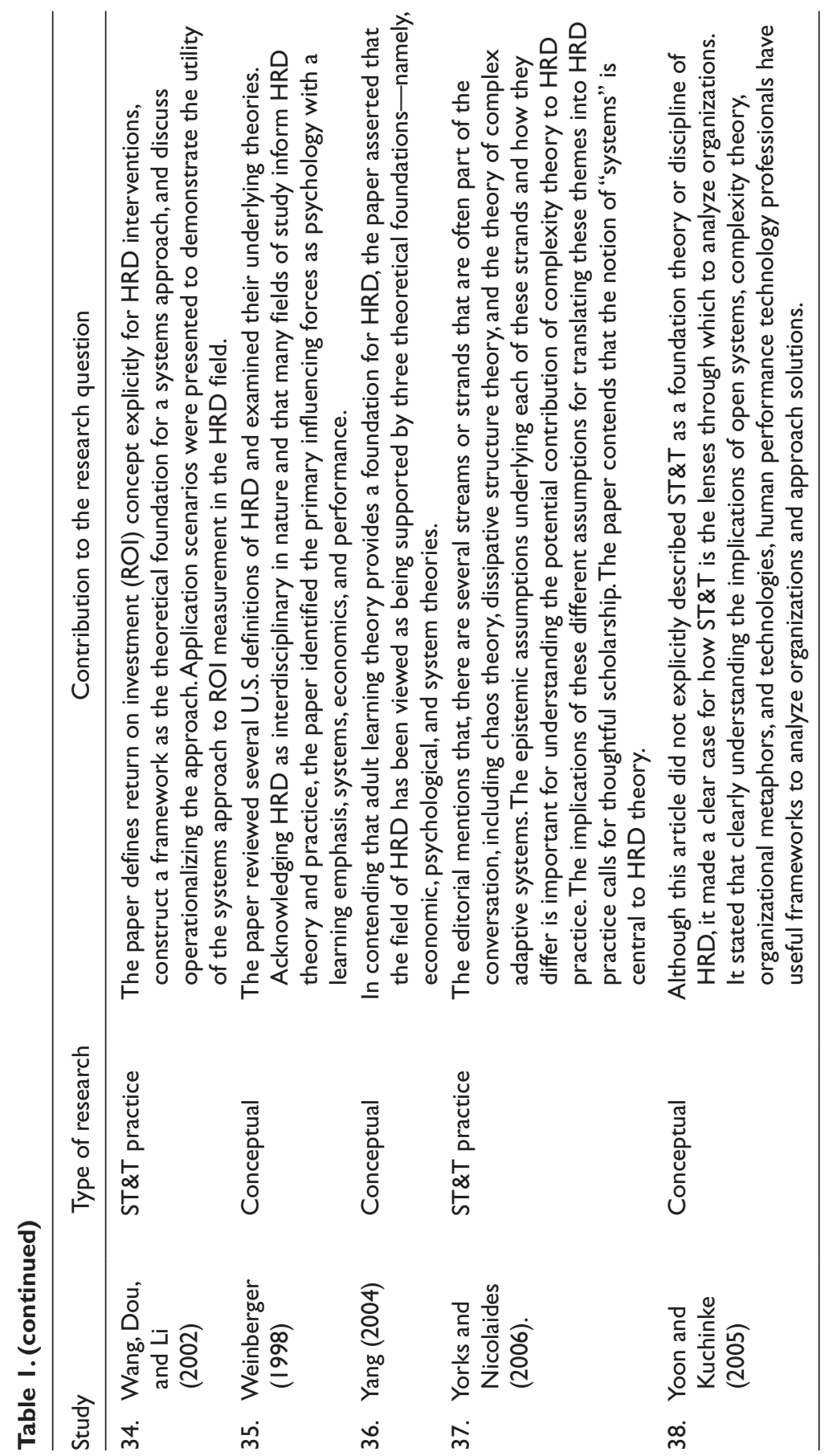


1997). Swanson (1999b, pp. 2-3) developed a three-legged theoretical foundations consisting of psychology, economics, and systems theories. Although McLean (1999) disagrees with Swanson's three-legged foundational theory, he considers HRD as having many varied disciplines as its foundation including ST\&T as key component. Jacobs (1989), a strong proponent of a unifying theory for HRD, argues that such a unifying theory should be based on systems theory. Of the 13 respondents who completed the final round of the Delphi study by McGuire and Cseh (2006) identified adult learning, systems theory, and psychology as the three main disciplinary foundations of HRD. Ardichvili (2008) in reviewing the panel discussion on "theory building in HRD" at the European HRD conference in Lille, France, in May 2008 proposed that the "Vygotskian cultural-historical activity theory (CHAT), with its grounding in systems theory, and its emphasis on interlocking systems of human activities, . . . is ideally suited to research in HRD" (p. 543). The systematic review identified several other HRD scholars who have articulated the importance of systems theory in research, practice as reported in Table 1.

There is a dearth of HRD literature on the reasons for the gap between theory and practice of ST\&T in HRD. However, general research to practice gap within HRD is substantially discussed. For example, Iles and Yolles (2003) have argued that HRD's "emphasis on consensus and participation, its narrow view of effectiveness, its inability to address issues of power, politics and culture, its ethnocentrism and cultural bias" (p. 29 ) are evidence of the gap between theory and practice. Several literature have also pointed to the gap between HRD scholarship and practice (e.g., Kuchinke, 2004; Short, 2006; Short, Keefer, \& Stone, 2009) with Kuchinke (2004) contending that most HRD research are conducted in a positivistic framework, without addressing or fully capturing the complex, the intangibles, and the vexing problems faced by practitioners and thus creating a gap between research and practice.

From the SER only one study has empirically proven that ST\&T is a foundational discipline or theory in HRD, but the overall evidence from the systematic review indicates that ST\&T is generally seen as a foundational discipline or an underlying theory of HRD. If ST\&T is a foundational theory, then one important question is whether future HRD professionals are being adequately trained to understand the importance and role of ST\&T in the research and practice of HRD? The following section of this article attempts to address this question.

\section{Mapping of Course Offerings in Leading HRD Departments}

HRD graduate-level course offerings within 33 identified universities were mapped to identify the level of ST\&T teaching and learning in various HRD curricula. The selected universities are all universities which were part of the Academy of Human Resource Development's Program Excellence Network (PEN) as of November 2010. "These academic programs are committed to strengthening HRD academic programs and promoting excellence in teaching HRD. The PEN provides a forum 
for its members to explore, learn, and work together to shape the future direction of HRD education" (AHRD, 2009). Out of the 33 universities mapped only the Department of Human Development and Family Science, Ohio State University, Ohio, USA, appears to have a full course of study in General Systems Theory $(8,804$ credits) and the University of Minnesota has a 1-credit course on Systems Foundations of HRD.

A compelling argument and critique of this mapping exercise may be made that reviewing the course titles may not indicate the degree to which ST\&T is integrated into the curriculum. This is a valid critique and an empirical study, which is outside the scope of this study, is required to fully substantiate the conclusion drawn from the mapping exercise. It is also important to note that considering the breadth, boundaries, and parameters of ST\&T, it may be expected that a full course of study will not be embedded in another course without the mention of ST\&T or its emergent theories and applications such as complexity theory and CAS in their description.

This circumstantial result from the mapping analysis is however, consistent with existing literature. In a study by Kuchinke (2002) in which the content areas covered in core or required curricula of graduate HRD programs in 55 universities were ranked, ST\&T as content area was not in the 33 areas listed. It may likely be that aspects of ST\&T are embedded in some of the programs and courses but are not seen as standalone courses. Most of the programs have foundations of HRD where it is likely that some level of systems theory is discussed, but not to any detail that can translate into practice, such as ST\&T courses that exists in some Public Policy Schools and Engineering Departments, for example Richardson (2012).

Quite surprisingly, the "Academic Standards Committee" of the AHRD in discussing curriculum as one of the seven core areas of the standards failed to mention systems theory or even any of its main applications. The Committee listed the "Core Theory in HRD" through which the "curriculum should provide an understanding of perspectives that form the context for human resource development" (AHRD, 2008 p. 2) and made no mention of systems theory as part of the topics that needed to be covered. The Committee is however, made up of some of the leading and finest scholars in the field of HRD who have clearly articulated the importance of systems theory in the research, theory, and practice of HRD. A persuasive argument can be made that the topics selected may inevitably include the discussion of systems theory and that it is embedded in them, just as psychology, anthropology, or economics for instance were not listed as topics to be covered. The flaw in this argument is that unlike the other disciplinary foundations of HRD, ST\&T is not an established field of study in most undergraduate education programs and therefore the likelihood of most of the graduate students in HRD coming into the program with knowledge of ST\&T is low. This in itself is one of the main reasons why there is disconnect between theory and practice. Unlike the other disciplinary foundations, most universities and faculty have not fully recognized systems theory as field that requires separate curricula. Because of that, HRD students have no access to any such courses in other departments to compensate for lack of it in their own academic programs. 
"Research on university HRD education indicates that despite the increasing demands of HRD practice and the broadening of the knowledge domains and skill sets required of successful HRD professionals, university departments appear to be slow to reform their curricula" (Kuchinke, 2007, p. 112) and full incorporation of ST\&T could be cited as a typical example. The onus is therefore on HRD faculty to make conscious effort to get ST\&T and its emerging applications into the curricula by working with colleagues in other disciplines.

The lack of ST\&T in the HRD curricula gives credence to the perception that systems theory in HRD has just been reduced to aphorisms and students are not well equipped for the use of ST\&T in HRD practice.

\section{Discussions, Implications, and Recommendations}

The evidence gathered from the systematic review of the literature clearly answers the main research question. Systems theory as foundational theory in HRD is broadly accepted, however, its relevance and use in the practice of HRD remains a myth. Why is there such a disconnection between theory, research, and practice? This study can at least point to one likely barrier militating against the use of ST\&T in HRD practice: the mapping exercise of some of the leading universities with HRD programs indicates the low level of incorporation of systems theory as core part of the curricula.

Most of the discussions on systems theory gathered from the systematic review seem to be definitional and little is said about implication for practice and only one of the studies is empirical. The existing HRD literature does not appear to move beyond broad discussion of systems theory and into specifics. It is also clear that HRD research has been restricted to only one aspect of ST\&T-hard systems thinking. HRD uses a "linear epistemology" to generate "input-process-output" type models, such as ADDIE. This in itself is a barrier militating against the full use of ST\&T in HRD practice. As Senge, Smith, Kruschwitz, Laur, and Schley (2010) have contended: we are at the end of the industrial age and the reality in practice for the 21 st century is nonlinear systems thinking. Consequently, the HRD professional looking for recommendations on how to implement or use systems theory in their work receives no guidance from the HRD literature and may have to look elsewhere. Similarly, any person interested in case studies or research that describe how ST\&T has been applied or implemented in organizations will find very little help from the HRD literature. This observation is aptly substantiated by Yorks and Nicolaides (2006) in their editorial in HRDR where they concluded that there is the need to build "a particular stream of serious scholarship" (p. 147). Having said this, I must hasten to add that ST\&T has in several ways directed the way HRD has evolved as a discipline or field of study. Apart from the broad recognition of systems theory as a foundational theory in HRD, the concepts of ST\&T have been used to situate the never ending debate and search for the definition of HRD. Roth 
(2004), for example, has contended that ST\&T "might be the best approach for understanding HRD, its boundaries, and those things that seem to have the strongest connections to it" (p. 14). Daley and Jeris (2004) have also concluded that the ST\&T concept of relationships between systems and subsystems is how the relationship between continuing professional education (CPE), HRD, and workforce development should be seen. The concept of organizational learning and learning organizations that forms substantial part of HRD scholarship and research have direct lineage from ST\&T. These types of contributions to scholarly research in ST\&T in HRD have therefore shaped the way HRD has evolved and continues to evolve as discipline especially with regards to it boundaries.

So what are the practical implications of ST\&T for HRD? It is obvious that, many features of ST\&T such as order, control, growth, synergy, emergence, identity, structure, equifinality, multifinality, information, planning, prediction, feedback, adaptation, stability - are part of the human and organizational development process, and these are what is needed to be articulated and used in practice. The lack of articulation of these practical applications, in the scholarly literature, teaching, and research may, wrongly or rightly, lend credence to commentators who have argued that "much of the HRD literature is based on fads and gimmicks without any conceptual foundation" (Garavan, Heraty, \& Barnicle, 1999, p. 172).

Another challenge to the use of ST\&T in HRD practice is that it is very intellectually demanding in its application. "It requires multi-disciplinary approaches. And by its very nature, it needs to take a wide range of trends, actors, events and patterns. It requires more investment in a wider range of staff skills, a different organizational structure, and a different set of values and perspectives" (Morgan, 2005).

Although Swanson (2001), for example, strongly favors the use of system theory and tools, this has not been very well addressed in HRD. Despite developments in approaches and methodologies, the predominant "systems" models in use in HRD remain rooted in rather simple "input-transformation-output" systems models (Iles $\&$ Yolles, 2003). The broad agreement that ST\&T provides a sound theoretical foundation for HRD owes much to the work of Swanson, who has undoubtedly done more than most to underpin the concept of systems foundations of HRD. Paradoxically, there is a tendency within the ST\&T in HRD literature of presenting his concepts as a series of clichéd aphorisms without any deeper articulation of its importance to research and practice, a trend he may be guilty himself. For example, Swanson (2007) stated that chaos theory, an important aspect of systems theory, is important to HRD as it provides the perspective that an organization must stay successful amidst the chaos that it faces. However, direct discussion of the ideas that comprise chaos theory and how they are beneficial to the HRD professional in practice were not included. Most ST\&T approaches often articulated in the HRD literature generally involve a linear process of ADDIE that may have limitations in addressing organization complexity, power and interpersonal dynamics, and organization culture (Bierema \& Eraut, 2004). "The challenge facing us all is how to move 
past slogans about accelerating learning and systems thinking to useful tools that help us understand complexity, design better operating policies, and guide effective change" (Sterman, 2001, p. 10).

One branch of systems thinking - systems dynamics is a method to enhance learning in complex systems and it can be a powerful field of study that can have significant practical application in ST\&T in HRD. Systems dynamics modeling and simulation could be used as an effective tool for any formulation and understanding of issues of relevance in HRD practice. Systems models give the chance for experimentation and reflection and thus can facilitate the complete understanding of the complex environment in which HRD professionals operate (Yawson, 2010). The real advantage of systems dynamics in HRD practice may lie in the creation of feedback loops to facilitate learning (Grieves, 2010). If therefore HRD practitioners "could learn how to understand their own systems dynamics, then they could understand the complex relationships and underlying properties of their own systems" (Grieves, 2010 , p. 161). There is superficial plausibility in the proposition that HRD professionals should become more knowledgeable in ST\&T application in practice. It is therefore important that HRD professionals learn about interrelationships through feedback loops that illustrate causality, which will enhance more reflection on the processes of HRD practice, and in particular time delays it takes to effect organizational change.

Another observation from the lack of practical application of ST\&T by HRD professionals is the inertia within HRD academic research to clearly lay out the practical implications. This inertia is borne out of what Jayanti (2011) described as overreliance on a linear epistemology that has several limitations, "including a tendency to privilege particular Western cultural and masculine worldviews, short-term measures, and effects close to the organization" (p. 101). While, in contrast, consultants make a living from selling of systems theory applications "by focusing on creating a commercially attractive template and presenting it to clients" (Grieves, 2010, p. 160).

The nature of dynamic complexity of challenges HRD professionals have to deal with in the 21 st century lends itself to a whole new paradigm of approach to how future HRD professionals are trained (Senge et al., 2010). Senge et al. (2010) contend that we are at the end of the industrial age and a new revolution is emerging out of the industrial "bubble" and the people leading this revolution like HRD professionals must demonstrate mastery of three core areas that undergird organizational learning: learning how to see the larger systems, understanding the importance of collaborating across boundaries "that previously divided them from others within and outside their organizations"(p. 44), and "moving away from reactive problem solving mode to creating futures they truly desire"(p. 44).

The usefulness of linear epistemology and the hard systems approach in addressing tame problems is not in contention. The contention is that linear epistemology cannot be the dominant epistemology of practice and that dynamic complexity of 
challenges confronted by HRD professionals in their daily research and practice requires a nonlinear epistemology of practice (Jayanti, 2011), rather than reductive or linear thinking or processes of normal science. As the findings of SER indicated, there is no doubt that ST\&T is seen and recognized as a foundational theory of HRD. The myth is its lack of use in HRD research and practice for a theory recognize as a foundational theory and also necessary for 21 st-century HRD practice. The foregoing and the mapping analysis lead to a recommendation for the incorporation of more ST\&T courses into the HRD undergraduate and graduate curricula. These courses should be designed to help prepare future HRD professionals to effectively operate and be competitive in the nonlinear dynamical world of the 21 st century. The following courses could be of interest:

- Introduction to systems theory and thinking: a 3-credit course to serve undergraduate students both within and outside HRD cohort.

- Systems thinking and theory in HRD: a 3-credit graduate-level course

- Systems dynamics - theory and practice: a 3-credit graduate-level course

- Advanced systems theory and thinking in HRD: an advanced course for doctoral students and masters students, interested in research careers; with any of the two earlier listed graduate courses being a prerequisite.

The scope of this study and space limitations will not allow for the content of these proposed courses to be detailed here. It must also be acknowledged that incorporating all these into the HRD curriculum may seem an overkill; on the contrary it will underscore the interdisciplinary nature of HRD and attract students from other disciplines to take more HRD courses.

Another recommendation worth considering is the creation of formal collaboration between AHRD and the Systems Dynamics Society and/or the International Society for the Systems Sciences - two of the main organizations in the field of ST\&T. The collaboration can take different shapes including research partnership between members and joint conferences. The basis for this recommendation is that disciplinarity is no longer the overriding scheme for knowledge creation and organization (Mehta, 2002) especially for an interdisciplinary field, such as HRD and systems sciences. Knowledge creation is now transdisciplinary, more reflexive, nonlinear, complex, and hybridized (Yawson, 2009), making such interdisciplinary collaboration extremely important. The social robustness and inclusivity of HRD curriculum will determine the value of knowledge and how ST\&T in HRD can be of practical value.

Another important recommendation is the commissioning of study to critically review the curriculum of HRD schools to determine the level of ST\&T and its emergent applications; and how it can in reality contribute to research, teaching, and practice of HRD. This is a practical way to place HRD in the forefront of producing 21 st-century professionals in leading adaptive change. 


\section{Conclusion and Limitations of Study}

ST\&T as a foundational theory in HRD is not in doubt and it is required for HRD research and practice. It, however, remains a myth due to lack of epistemology of practice, although it is broadly agreed that it is one of the main foundations of HRD. The disconnect between practice and theory which is making it more of a myth than reality can be traced to several factors such as lack of ST\&T curriculum in most HRD departments, the dominance of linear epistemology in most HRD models, and lack of scholarly and empirical research articulating the implications of ST\&T in HRD practice. There is, therefore, the need to re-conceptualize HRD in the context of the rise in the substance of complexity theories and fully acknowledge that there is a parallel outlook and conversation that needs to take place within the field (Iles \& Yolles, 2003; Yorks \& Nicolaides, 2006).

Mapping analysis of course offerings of 33 of top HRD departments in U.S. universities; the previous studies by Kuchinke where ST\&T did not rank in the first 33 content areas of HRD curriculum; and the failure of the "Academic Standards Committee" of AHRD to acknowledge ST\&T or even any of its main applications when discussing curriculum as one of the seven core areas of the standards in HRD, are all evidence to the myth of ST\&T in HRD. To improve the ability of HRD professionals being produced by the universities to learn about and manage complex systems, there is the need to incorporate into the curricula courses that will equip them with the "tools capable of capturing the feedback processes, stocks and flows, time delays, and other sources of dynamic complexity" (Sterman, 2001, p. 17).

One important aspect of this study is the introduction of SER as a research methodology in HRD. Although the full complement of SER as used mostly in medical intervention research was not used; the adaptation of the overall process in an HRD research may serve as an important research approach. It is a research approach that can be refined and used in HRD research and scholarship to complement or serve as alternative to integrated literature reviews and an obvious departure from the traditional narrative reviews. As it is done in the medical field the AHRD can set up a committee (Special Interest Group) on SER.

\section{Limitations of Study}

This study comes with some limitations. First of all, the systematic review was restricted to English language journals that are found in the main databases. Articles that do not cite the search terms in English, and journals that are not included in the main databases, were omitted from the analysis. In addition, the search in the main databases was not exhaustive, since it excluded books that are not online and unpublished conference proceedings with exception of those published in special editions of journals. Another limitation is to do with the scope of mapping analysis. All the schools selected are U.S. based. It may be very possible that although some of the courses do not mention systems theory in the labels, the content of the course may contain substantial lessons on ST\&T. 


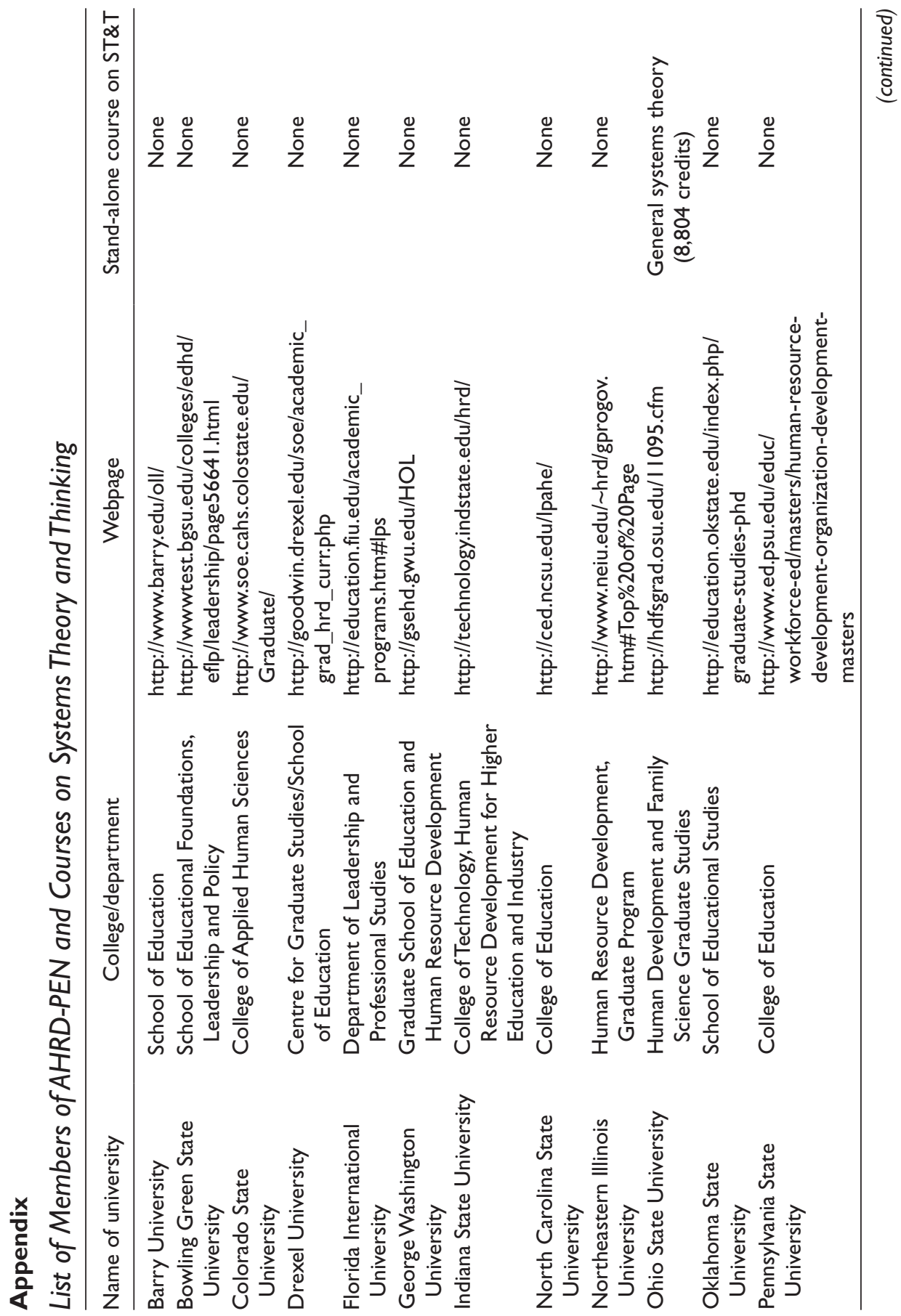




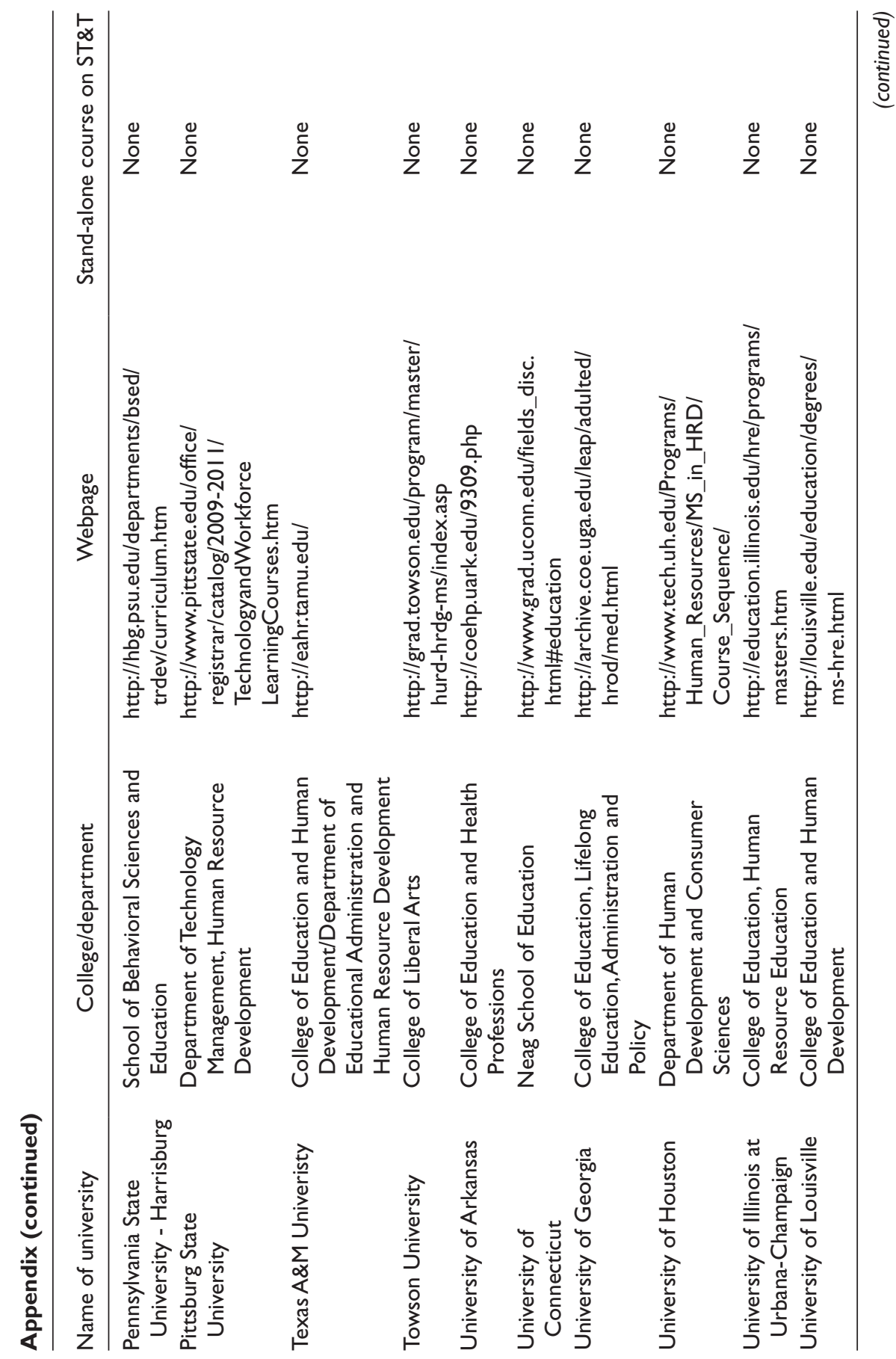




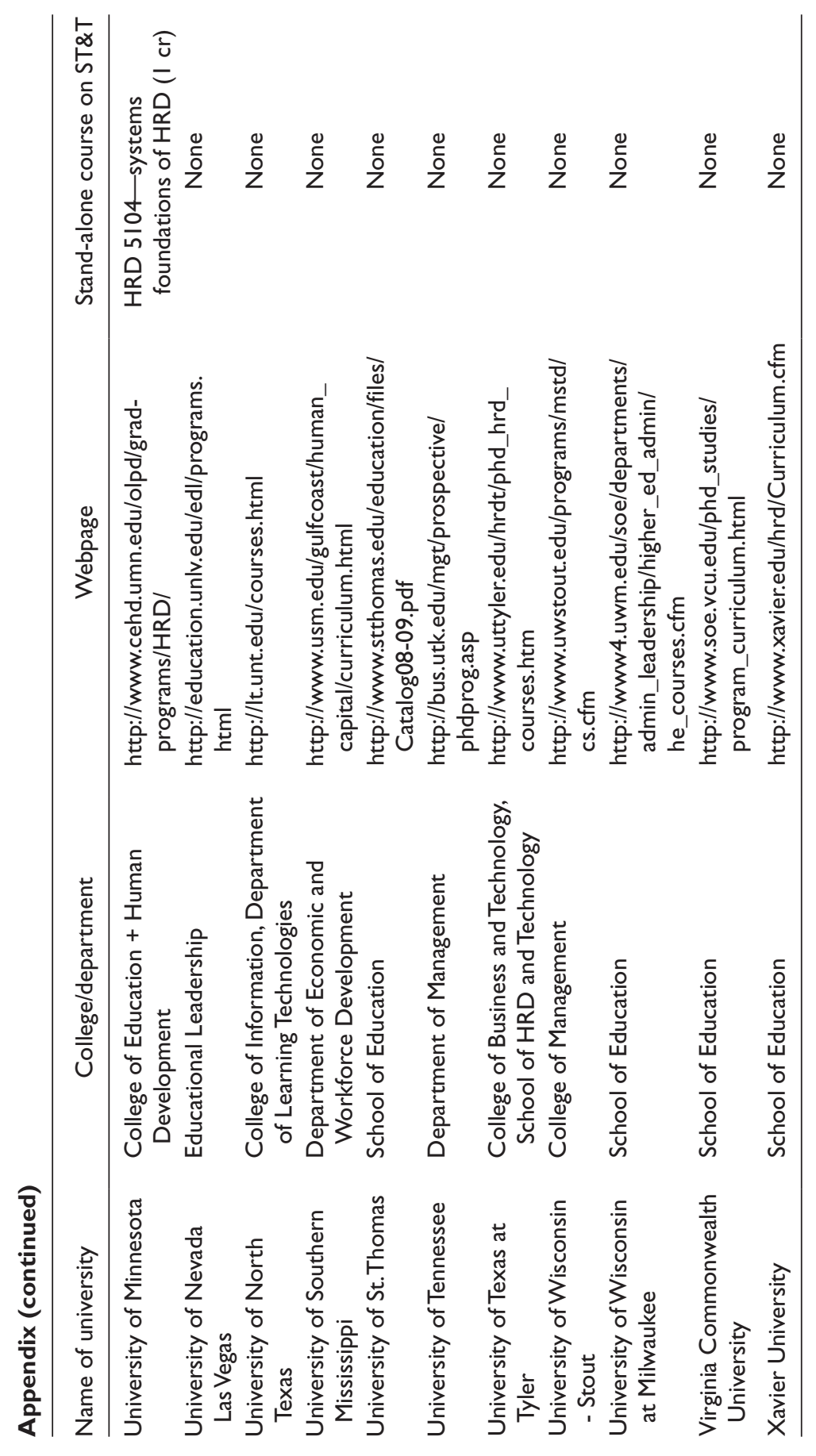




\section{Acknowledgments}

I would like to thank Professor Alexandre (Sasha) Ardichvili of the College of Education and Human Development, University of Minnesota for encouraging me in putting this article together and for his valuable critique of the final draft. I also thank my dear wife, Ivy Yawson, for using part of her valuable annual leave to help with the mapping studies and text mining.

\section{Declaration of Conflicting Interests}

The author declared no potential conflicts of interest with respect to the research, authorship, and/or publication of this article.

\section{Funding}

The author received no financial support for the research, authorship, and/or publication of this article.

\section{References}

AHRD. (2007). Theory development in human resource development bibliography. Theory Committee, Bowling Green, OH: Academy of Human Resource Development.

AHRD. (2008). Standards for HRD graduate program excellence. Saint Paul, MN: Academic Standards Committee of the Academy of Human Resource Development (AHRD).

AHRD. (2009). Academic programs in HRD. St. Paul, MN: Program Excellence Network (PEN), Academy of Human Resource Development (AHRD). Retrieved from http://www. ahrd.org/displaycommon.cfm?an=1\&subarticlenbr $=10$

Ardichvili, A. (2008). Can there be a domain-specific knowledge base in HRD? Reflections on the Lille symposium. Human Resource Development International, 11, 539-544.

Bánáthy, B. H. (1996). Designing social systems in a changing world (contemporary systems thinking). New York, NY: Kluwer Academic (Springer).

Bánáthy, B. H. (2000). Guided evolution of society: A systems view (contemporary systems thinking). New York, NY: Kluwer Academic (Springer).

Bierema, L. L., \& Eraut, M. (2004). Workplace-focused learning: Perspective on continuing professional education and human resource development. Advances in Developing Human Resources, 6(1), 52-68. doi:10.1177/1523422303260859

Boaz, A., Ashby, D., \& Young, K. (2002). Systematic reviews: What have they got to offer evidence based policy and practice? London, UK: Evidence Based Policy and Practice. Retrieved from http://kcl.ac.uk/content/1/c6/03/45/85/wp2.pdf

Brookfield, S. (1992). Developing criteria for formal theory building in adult education. Adult Education Quarterly, 42(2), 79-93.

Callahan, J. L. (2010). Constructing a manuscript: Distinguishing integrative literature reviews and conceptual and theory articles. Human Resource Development Review, 9, 300-304.

Chalofsky, N. (1992). A unifying definition for the human resource development profession. Human Resource Development Quarterly, 3, 175-182.

Checkland, P., \& Scholes, J. (1990). Soft Systems methodology in action. Chichester, UK: Wiley. 
Cook, D. J., Mulrow, C. D., \& Haynes, R. B. (1997). Systematic reviews: Synthesis of best evidence for clinical decisions. Annals of Internal Medicine, 126, 376-380. Retrieved from http://www.ncbi.nlm.nih.gov/pubmed/9054282

CRD (2009). Systematic reviews: CRD's guidance for undertaking reviews in health care. Centre for Reviews and Dissemination (CRD), University of York, Layerthorpe, York, UK: York Publishing Services.

Daley, B. J., \& Jeris, L. (2004). Boundary spanning. Advances in Developing Human Resources, 6(1), 5-8. doi:10.1177/152342230461001

Davies, P. (2000). The relevance of systematic reviews to educational policy and practice. Oxford Review of Education, 26, 365-378. doi:10.1080/3054980020001882

Davies, P. (2003). Systematic reviews: How are they different from what we already do? In L. Anderson \& N. Bennett (Eds.), Developing educational leadership (pp. 25-36). London, UK: SAGE. doi:10.4135/9780857024381

Ditto, W., \& Munakata, T. (1995). Principles and applications of chaotic systems. Communications of the ACM, 38(11), 96-102.

Dixon-Woods, M. (2006). Critical interpretive synthesis: A brief introduction. Systematic reviews 1: ESRC methods festival (p. 26). Oxford, UK: EPPI-Centre, Social Science Research Unit, Institute of Education, University of London.

Dixon-Woods, M., Agarwal, S., Jones, D., Young, B., \& Sutton, A. (2005). Synthesizing qualitative and quantitative evidence: A review of possible methods. Journal of Health Services Research Policy, 10(1), 45-53.

Engel, P. G. H. (1997). The social organization of innovation. A focus on stakeholder interaction. Amsterdam, The Netherlands: KIT Press.

EPPI. (2010). EPPI-centre methods for conducting systematic reviews. Evidence for Policy and Practice (p. 27). London, UK: EPPI-Centre, Social Science Research Unit, Institute of Education, University of London.

Garavan, T. N., Heraty, N., \& Barnicle, B. (1999). Human resource development literature: Current issues, priorities and dilemmas. Journal of European Industrial Training, 23, 169-179. doi:10.1108/EUM0000000004567

Gasteen, M. (2010). Research and evidence division systematic review program. Systematic review program (pp. 1-3). London, UK: DFID.

Goodwin, G. M., \& Geddes, J. R. (2004). Introduction to systematic reviews. Journal of psychopharmacology, 18, 249-250. doi:10.1177/0269881104042629

Grieves, J. (2010). Organizational change: Themes and issues (1st ed.). New York, NY: Oxford University Press. ISBN 978-0-19-921488-4.

Harden, A., \& Thomas, J. (2005). Methodological issues in combining diverse study types in systematic reviews. International Journal of Social Research Methodology, 8, 257-271. doi:10.1080/13645570500155078

Hartshorn, G. R. (1989). Pushing the frontiers of systems thinking: Implications for human resource development. In D. B. Gradous (Ed). Systems theory applied to human resource development (pp. 83-90). Alexandria, VA: American Society for Training and Development. 
Hemingway, P., \& Brereton, N. (2009). What is a systematic review? Evidence-based medicine (2nd ed., pp. 1-8). Sheffield, UK: Hayward Medical Communications.

Heylighen, F. (2000). Cybernetics and systems theory. In, F. Heylighen, C. Joslyn, \& V. Turchin (Eds.), Principia cybernetica web. Brussels, Belgium: Principia Cybernetica. Retrieved from http://cleamc11.vub.ac.be/cybsysth.html

Heylighen, F., Joslyn, C., \& Turchin, V. (Eds.). (2000). Principia cybernetica web. Brussels, Belgium: Principia Cybernetica. Retrieved from http://cleamc11.vub.ac.be/cybsysth.html

Hickman, G. R. (2010). Leading change in multiple contexts: Concepts and practices in organizational, community, political, social, and global change settings. Thousand Oaks, CA: SAGE.

Higgins, J. P. T., \& Green, S. (Eds.). (2009). Cochrane handbook for systematic reviews of interventions. Version 5.0.2. The Cochrane Collaboration. Retrieved from: www.cochranehandbook.org

Holton, E. F., III. (1999). Performance domains and their boundaries. Advances in Developing Human Resources, 1, 26-46.

Houchin, K., \& MacLean, D. (2005). Complexity theory and strategic change: an empirically informed critique. British Journal of Management, 16(2), 149-166. doi:10.1111/j.14678551.2005.00427.X

Iles, P., \& Yolles, M. (2003). Complexity, HRD and organisation development: Towards a viable systems approach to learning, development and change. In M. Lee (Ed.), HRD in a complex world, studies in human resource development (Vol. 54, pp. 25-41). Oxford, UK: Routledge.

Jacobs, R. (1989) Systems theory applied to human resource development. In D. Gradous (Ed.), Systems theory applied to human resource development, theory to practice monograph (pp. 27-60), Alexandria, VA: ASTD Press.

Jayanti, E. B. (2011). Through a different lens: A survey of linear epistemological assumptions underlying HRD models. Human Resource Development Review, 10(1), 101-114.

Kuchinke, K. P. (2001). Why HRD is not an academic discipline. Human Resource Development International, 4, 291-294. doi:10.1080/13678860110059357

Kuchinke, K. P. (2002). Institutional and curricular characteristics of leading graduate HRD programs in the U.S. Human Resource Development Quarterly, 13(2), 127-144.

Kuchinke, K. P. (2004). Theorizing and practicing HRD: Extending the dialogue over the roles of scholarship and practice in the field. Human Resource Development International, 7 , 535-539. doi:10.1080/1367886042000299825

Kuchinke, K. P. (2007). Birds of a feather? The critique of the North American Business School and its implications for educating HRD practitioners. Human Resource Development Review, 6(2), 111-126.

Lee, M. M. (2003). The complex roots of HRD. In M. M. Lee (Ed.), HRD in a complex world (pp. 7-24). London, UK: Routledge.

Levy, D. (1994). Chaos theory and strategy: Theory, application, and managerial implications. Strategic Management Journal, 15, 167-178.

McGuire, D., \& Cseh, M. (2006). The development of the field of HRD: A Delphi study. Journal of European Industrial Training, 30, 653-667.

McKelvey, B. (1999). Avoiding complexity catastrophe in coevolutionary pockets: Strategies for rugged landscapes. Organization Science, 10, 294-321. doi:10.1287/orsc.10.3.294 
McLagan, P. A. (1989). Systems model 2000: Matching systems theory to future HRD issues. In D. B. Gradous, (Ed.), Systems theory applied to human resource development (pp. 65-86). Alexandria, VA: American Society for Training and Development.

McLean, G. N. (1999). Get out the drill, glue and more legs, Human Resource Development International, 2(1), 6-7.

Mehta, M. D. (2002). Regulating biotechnology and nanotechnology in Canada: A post-normal science approach for inclusion of the fourth Helix. Paper presented at the International Workshop on Science, Technology and Society: Lessons and Challenges, National University of Singapore, Singapore.

Morgan, P. (2005). The idea and practice of systems thinking and their relevance for capacity development. Maastricht, The Netherlands: European Centre for Development Policy Management.

ODI. (2012). Making systematic reviews work for international development research. Briefing Paper 1: Researching livelihoods and services affected by conflict (Vol. 44, p. 4). London, UK: Overseas Development Institute (ODI).

Ossimitz, G. (2000). Development of systemic thinking. München, Germany: Profil.

Passmore, D. L., III (1997).Ways of seeing: Disciplinary bases of research in HRD. In R. A. Swanson \& E. F. Holton (Eds.), Human resource development research handbook (pp. 114137). San Francisco, CA: Berrett-Koehler.

Petticrew, M. (2001). Systematic reviews from astronomy to zoology: Myths and misconceptions. BMJ (Clinical research ed.), 322, 98-101.

Petticrew, M., \& Roberts, H. (2006). Systematic reviews in the social sciences: A practical guide. Malden, MA: Blackwell Publishing.

Pope, C., Mays, N., \& Popay, J. (2007). Synthesizing qualitative and quantitative health evidence: A guide to methods. Maidenhead, UK: Open University Press.

Porter, L., Schoeneck, D., Frey, P., Hicks, D. M., \& Libaers, D. P. (2007). Mining the Internet for competitive technical intelligence. Competitive Intelligence Magazine, 10(5), 24-28.

Raelin, J. A. (2007). Toward an epistemology of practice. The Academy of Management Learning and Education, 6, 495-519.

Richardson, G. P. (2012). GPR home page. Albany, NY: Courses. Retrieved from http://www. albany.edu/ gpr/Courses.html

Richmond, B. (1993): Systems thinking: Critical thinking skills for the 1990s and beyond. System Dynamics Review, 9(2), 113-133.

Roth, G. L. (2004). CPE and HRD: Research and practice within systems and across boundaries. Advances in Developing Human Resources, 6(1), 9-19. doi:10.1177/1523422303260417

Ruona, W. E. A. (2008). Systems theory as a foundation for human resource development. In R. A. Swanson, \& E. F. Holton III, Foundations of human resource development (2nd Ed, pp. 128-136). San Francisco, CA: Berrett-Koehler Publishers.

Schneider, M., \& Somers, M. (2006). Organizations as complex adaptive systems: Implications of complexity theory for leadership research. The Leadership Quarterly, 17, 351-365.

Senge, P., Smith, B., Kruschwitz, N., Laur, J., \& Schley, S. (2010). The necessary revolution. New York, NY: Crown Publishing Group.

Short, D. C. (2006). Closing the gap between research and practice in HRD. Human Resource Development Quarterly, 17, 343-350. doi:10.1002/hrdq 
Short, D. C., Keefer, J., \& Stone, S. J. (2009). The link between research and practice: Experiences of HRD and other professions. Advances in Developing Human Resources, 11, 420437. doi:10.1177/1523422309343278

Sterman, J. (2000). Business dynamics-Systems thinking and modeling for a complex world. Boston, MA: Irwin McGraw-Hill.

Sterman, J. D. (2001). System dynamics modeling: Tools for learning in a complex world. California management review, 43(1), 8-25.

Straussfogel, D., \& von Schilling, C. (2009). Systems theory. In R. Kitchin \& N. Thrift (Eds.), International encyclopedia of human geography (1st ed., Vol. 1, pp. 151-158). Oxford, UK: Elsevier.

Swanson, R. A. (1999a). HRD Theory: Real or imagined? Human Resource Development International, 2(1), 2-5.

Swanson, R. A. (1999b). The foundations of performance improvement and implications for practice. Advances in Developing Human Resources, 1, 1-25.

Swanson, R. A. (2001). Human resource development and its underlying theory. Human Resource Development International, 4(3), 299-312.

Swanson, R. A., \& Holton, III, E. F (2008). Foundations of human resource development (2nd ed, pp. 18-19 \& 108-109). San Francisco, CA: Berrett-Koehler Publishers.

Taleb, N. (2007). The black swan. New York, NY: Random House.

Tetenbaum, T. J. (1998). Shifting paradigms: From Newton to chaos. Organizational Dynamics, 26(4), 21-32.

Thomas, J., Brunton, J., \& Graziosi, S. (2010) EPPI-Reviewer 4.0: Software for research synthesis. EPPI-Centre Software. London, UK: Social Science Research Unit, Institute of Education.

Thomas, J., \& Harden, A. (2003). Practical systems for systematic reviews of research to inform policy and practice in education. In L. Anderson \& N. Bennett (Eds.), Developing educational leadership (pp. 39-53). London, UK: SAGE. doi:10.4135/9780857024381

Thomas, J., \& Harden, A. (2008). Methods for the thematic synthesis of qualitative research in systematic reviews. BMC Medical Research Methodology, 8, 45.

Torraco, R. J. (1997). Theory building research methods. In R. Swanson \& E. Holton, III (Eds.), Human resource development research handbook (pp. 114-137). San Francisco, CA: Berrett-Koehler.

Torraco, R. J. ( 2005). Writing integrative literature reviews: Guidelines and examples. Human Resource Development Review, 4, 356-367.

Tranfield, D., Denyer, D., \& Smart, P. (2003). Towards a methodology for developing evidenceinformed management knowledge by means of systematic review. British Journal of Management, 14, 207-222.

Vakili, K., Izadi, E. F., \& Moteabbed, S. (2007). Resisting dynamic structures in shifting toward "systems thinking." Proceedings of the 51st annual meeting of the ISSS, Tokyo, Japan.

van der Knaap, L. M., Leeuw, F. L., Bogaerts, S., \& Nijssen, L. T. J. (2008). Combining Campbell standards and the realist evaluation approach: The best of two worlds? American Journal of Evaluation, 29(1), 48-57. doi:10.1177/1098214007313024

Williams, G. P. (1997). Chaos theory tamed. Washington, DC: John Henry Press. 
Witten, I. H. (2004). Adaptive text mining: Inferring structure from sequences. Journal of Discrete Algorithms, 2(2), 137-159. doi:10.1016/S1570-8667(03)00084-4

Wright, R. W., Brand, R. A., Dunn, W., \& Spindler, K. P. (2007). How to write a systematic review. Clinical orthopaedics and related research, 455, 23-29. doi:10.1097/ BLO.0b013e31802c9098

Yawson, R. M. (2009). The ecological system of innovation: A new architectural framework for a functional evidence-based platform for science and innovation policy. In K. R. E Huizingh, S. Conn, M. Torkkeli, \& I. Bitran (Eds.). The future of innovation. Proceedings of XX ISPIM 2009 conference. Vienna, Austria: Wiley Higher Education. ISBN 978-952-214-766-0

Yawson, R. M., \& Kuzma, J. (2010), Systems mapping of consumer acceptance of agrifood nanotechnology. Journal of Consumer Policy, 33, 299-322.

Yorks, L., \& Nicolaides, A. (2006). Complexity and emergent communicative learning: An opportunity for HRD scholarship. Human Resource Development Review, 5(2), 143-147. doi:10.1177/1534484306287559

\section{List of References for the Systematic Evidence Review}

Ardichvili, A. (2008). Can there be a domain-specific knowledge base in HRD? Reflections on the Lille symposium. Human Resource Development International, 11, 539-544. doi:10.1080/13678860802417684

Brooks, K., \& Nafukho, F. M. (2006). Human resource development, social capital, emotional intelligence: Any link to productivity? Journal of European Industrial Training, 30(2), 117128. doi:10.1108/03090590610651258

Callahan, J. L., \& De Dávila, T. D. (2004). An impressionistic framework for theorizing about human resource development. Human Resource Development Review, 3(1), 75-95. doi:10.1177/1534484303261229

Chalofsky, N. (2007). The seminal foundation of the discipline of HRD: People, learning, and organizations. Human Resource Development Quarterly, 18, 431-442. doi:10.1002/hrdq.1212

Chenhall, E. C., \& Chermack, T. J. (2010). Models, definitions, and outcome variables of action learning: A synthesis with implications for HRD. Journal of European Industrial Training, 34, 588-608. doi:10.1108/03090591011070743

Chermack, T. J., \& Lynham, S. A. (2002). Definitions and outcome variables of scenario planning. Human Resource Development Review, 1, 366-383. doi:10.1177/1534484302013006

Collin, A. (2006). Conceptualising the family-friendly career: The contribution of career theories and a systems approach. British Journal of Guidance \& Counselling, 34, 295-307. doi:10.1080/03069880600769225

Dijk, M. S. V. (2004). Career development within HRD: Foundation or fad? Proceedings of the Academy of Human Resource Development Conference, USA. (pp. 771-778). Austin, TX.

Egan, T. M., Upton, M. G., \& Lynham, S. A. (2006). Career development: Load-bearing wall or window dressing? Exploring definitions, theories, and prospects for HRD-related theory building. Human Resource Development Review, 5, 442-477. doi:10.1177/1534484306294155

Garavan, T. N., Heraty, N., \& Barnicle, B. (1999). Human resource development literature: Current issues, priorities and dilemmas. Journal of European Industrial Training, 23, 169-179. doi:10.1108/EUM0000000004567 
Gradous, D. B. (Ed). (1989). Systems theory applied to human resource development. Alexandria, VA: American Society for Training and Development.

Harris, L. (2000). A theory of intellectual capital. Advances in Developing Human Resources, 2(1), 22-37. doi:10.1177/152342230000200104

Iles, P., \& Yolles, M. (2003). Complexity, HRD and organisation development: Towards a viable systems approach to learning, development and change. In M. Lee (Ed.), HRD in a complex world, studies in human resource development (Vol. 54, pp. 25-41). Oxford, UK: Routledge.

Kuchinke, K. P. (2004). Theorizing and practicing HRD: Extending the dialogue over the roles of scholarship and practice in the field. Human Resource Development International, 7, 535-539. doi:10.1080/1367886042000299825

Kuchinke, K. P. (2001). Why HRD is not an academic discipline. Human Resource Development International, 4, 291-294. doi:10.1080/13678860110059357

Lee, M. (2003). The complex roots of human resource development. In C. H. J. Gilson, I. Grugulis, \& H. Willmott (Eds.), CRM conference on critique and inclusivity: Opening the agenda (p. 1-20). Lancaster, UK.

Lynham, S. (2000). Theory building in the human resource development profession. Human Resource Development Quarterly, 11, 159-178. doi:10.1002/1532-1096(200022)11:2

Lynham, S., Chermack, T. J., \& Noggle, M. (2004). Selecting organization development theory from an HRD perspective. Human Resource Development Review, 3, 151-172. doi: $10.1177 / 1534484304265484$

McGuire, D., \& Cseh, M. (2006). The development of the field of HRD: A Delphi study. Journal of European Industrial Training, 30, 653-667. doi:10.1108/03090590610712304

McLean, G. N. (1998). HRD: A three-legged stool, an octopus, or a centipede? Human Resource Development International, 1, 375-377. doi:10.1080/13678869800000048

Roth, G. L. (2004). CPE and HRD: Research and practice within systems and across boundaries. Advances in Developing Human Resources, 6(1), 9-19. doi:10.1177/1523422303260417

Ruona, W. E. A. (2009). Systems theory as a foundation for human resource development. In R. A. Swanson \& E. F. Holton, III (Eds.), Foundations of human resource development (2nd ed., pp. 128-136). San Francisco, CA: Berrett-Koehler Publishers.

Sambrook, S. (2004). A “critical” time for HRD? Journal of European Industrial Training, 28, 611-624. doi:10.1108/03090590410566543

Swanson, R. (1995). Human resource development: Performance is the key. Human Resource Development Quarterly, 6, 207-214. Retrieved from

Swanson, R. A. (1999). HRD theory, real or imagined? Human Resource Development International, 2(1), 2-5. doi:10.1080/13678869900000002

Swanson, R. A. (2000). Theory and other irrelevant matters. Human Resource Development International, 3, 273-277. doi:10.1080/13678860050128465

Swanson, R. A. (2001). Human resource development and its underlying theory. Human Resource Development International, 4, 299-312. doi:10.1080/13678860110059311

Swanson, R. A. (2004). Brief on the foundations of human resource development. Colloquium Presentation at The University of Texas at Tyler. Tyler: The University of Texas at Tyler.

Swanson, R. A. (2007). Theory framework for applied disciplines: Boundaries, contributing, core, useful, novel, and irrelevant components. Human Resource Development Review, 6, 321-339. doi:10.1177/1534484307303770 
Swanson, R. A. (2008). Economic foundation of human resource development: Advancing the theory and practice of the discipline. Advances in Developing Human Resources, 10, 763 769. doi: $10.1177 / 1523422308324425$

Upton, M. G., \& Egan, T. M. (2010). Three approaches to multilevel theory building. Human Resource Development Review, 9, 333-356. doi:10.1177/1534484310380333

Wang, G. G., \& Holton, E. F. (2005). Neoclassical and institutional economics as foundations for human resource development theory. Human Resource Development Review, 4(1), 86108. doi: $10.1177 / 1534484304273733$

Wang, G. G, \& Wang, J. (2005). Human resource development evaluation: Emerging market, barriers, and theory building. Advances in Developing Human Resources, 7(1), 22-36.

Wang, G. G., Dou, Z., \& Li, N. (2002). A systems approach to measuring return on investment for HRD interventions. Human Resource Development Quarterly, 13, 203-224. doi:10.1002/ hrdq. 1024

Weinberger, L. A. (1998). Commonly held theories of human resource development. Human Resource Development International, 1(1), 75-93. doi:10.1080/13678869800000009

Yang, B. (2004). Can adult learning theory provide a foundation for human resource development? Advances in Developing Human Resources, 6(2), 129-145. doi:10.1177/1523422304263325

Yoon, S., \& Kuchinke, K. P. (2005). Systems theory and technology. Lenses to analyze an organization. Performance improvement, 44(4), 15-20.

Yorks, L., \& Nicolaides, A. (2006). Complexity and emergent communicative learning: An opportunity for HRD scholarship. Human Resource Development Review, 5(2), 143-147. doi:10.1177/1534484306287559

\section{Bio}

Robert M. Yawson is a senior research fellow with the Headwaters Group, USA, and an instructor at the Department of Organizational Leadership Policy and Development, University of Minnesota. He graduated from the University of Ghana with the BSc in biochemistry with chemistry and the master of philosophy in biochemistry. He also holds the postgraduate certificate in food management from the Hebrew University of Jerusalem, Israel, and an MS in science, technology and environmental policy from the Hubert H. Humphrey School, University of Minnesota. He is currently a $\mathrm{PhD}$ candidate in organizational leadership, policy and development at the University of Minnesota with dual specializations in human resource development, and workforce education; and agricultural, food, and environmental education. For 8 years prior to attending the University of Minnesota, he was the scientific secretary and later head of administration of the Food Research Institute, Ghana. He holds the Gary N. McLean Fellowship in HRD and the Turner/Oleson Fellowship in Agricultural Education. 